\title{
Study of Wear of Pitched Blade Impellers in a Solid-Liquid Suspension
}

\author{
I. Fořt, V. Kreibich, J. Marek
}

A study was made of the erosion wear of the blades of pitched blade impellers in a suspension of silicious sand $\left(C_{V}=5 \%, d=0.325 \mathrm{~mm}\right.$, degree of hardness "7.5") in water under a turbulent flow regime of agitated charge when complete homogeneity of the suspension was achieved. Two aims of the study were defined: the dependence of the rate of the erosion process of the impeller blades on impeller frequency of revolution and on the size of the mixing equipment. Experiments were carried out on pilot plant mixing equipment of two sizes (geometrically similar) made of stainless steel (diameters of cylindrical vessels $T_{1}=200 \mathrm{~mm}$ and $T_{2}=300 \mathrm{~mm}$, diameters of impellers $D_{1}=100 \mathrm{~mm}$ and $D_{2}=66.7 \mathrm{~mm}$, impeller off-bottom clearances $h_{1}=100 \mathrm{~mm}$ and $h_{2}=66.7 \mathrm{~mm}$, respectively) equipped with four radial baffles (width $b_{1}=30 \mathrm{~mm}, b_{2}=20 \mathrm{~mm}$, respectively) and an impeller with four inclined plane blades (pitch angle $\alpha=30^{\circ}, 45^{\circ}$, relative blade with $W / D=0.2$ ) made of rolled brass (Brinnel hardness 40-50 BM) always pumping the liquid downwards towards the flat vessel bottom. The wear of the impeller was described by an analytical approximation in exponential form with two parameters (the wear rate constant $k$ and the geometrical parameters of the worn blade C) calculated by the least squares method from the experimentally found profile of the worn leading edge of the impeller blades. While the wear rate constant exhibits a monotonous dependence on the pitch angle only, the geometric parameter is dependent both on the pitch angle and in linear form on the impeller tip speed. Thus in the procedure for scaling up the rate of erosion wear of the pitched blade impellers in a suspension of higher solid particle hardness, the decision process parameters are the impeller blade pitch angle and the impeller tip speed.

Keywords: pitched blade impeller, erosion wear, solid-liquid suspension, scaling up procedure.

\section{Introduction}

The erosion process of a pitched blade impeller in a solid liquid suspension of particles higher hardness was recently studied $[1,2,3,4]$, and a simplified two parameter model of the process was proposed and experimentally verified. The wear of the impeller can be described by an analytical approximation in exponential form. It follows from the above mentioned investigations that the wear rate constant does not depend on time, but that it significantly depends on the pitch angle. However, the geometric parameter depends both on the duration of the erosion period and on the blade pitch angle.

The velocity of two-phase flow affects the erosion process of a flat plate or impeller blade located in the stream of a solid-liquid suspension $[5,6]$. Moreover, when scaling up the mixing equipment it is desirable to take into consideration certain requirements of the procedure, because even when there is geometric similarity between the pilot plant and the industrial mixing unit it is necessary to fulfill suitable scaling up rules when using the results from pilot plant equipment experiments to design equipment on an industrial scale [7].

This study attempts to extend our knowledge about the mechanism of erosion wear of the blades of axial impellers in a solid-liquid suspension to determine the influence of the velocity of the two-phase flow around the blade, i.e. the impeller frequency of revolution, and to study the process in different sizes of mixing equipment, i.e. to look for the scaling up rules of the process.

\section{Experimental}

Experiments were carried out on pilot plant mixing equipment (see Fig. 1) of two geometrically similar sizes:

1. Larger unit: vessel diameter $T_{1}=300 \mathrm{~mm}$, height of liquid from bottom of vessel $H_{1}=300 \mathrm{~mm}$, diameter of impeller $D_{1}=100 \mathrm{~mm}$.

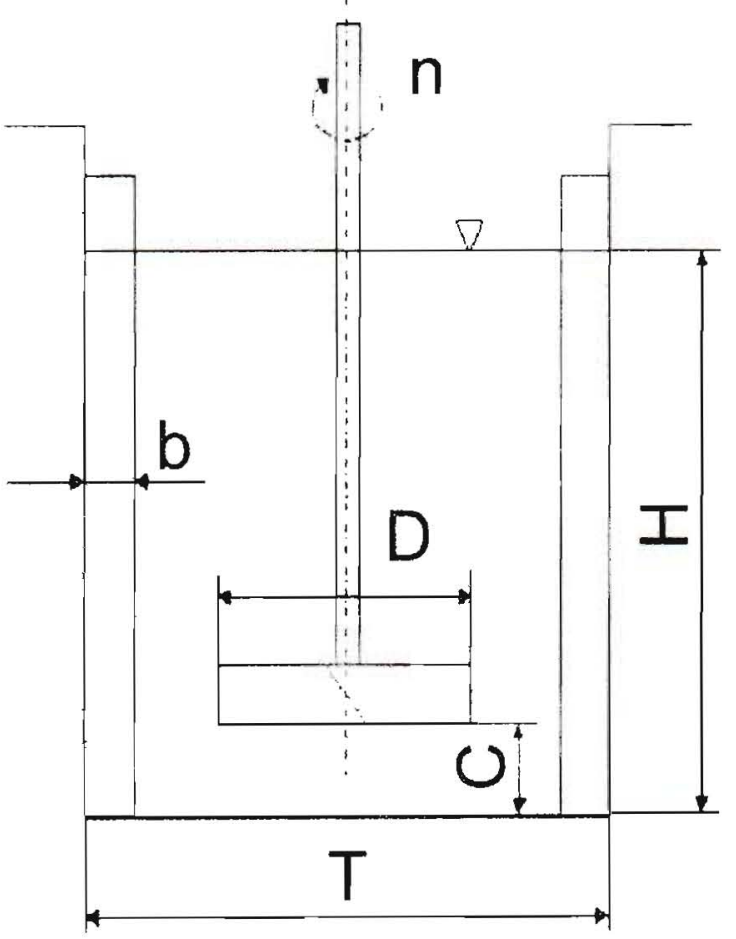

Fig. 1: Geometry of pilot plant mixing equipment $(\mathrm{H} / \mathrm{T}=1, \mathrm{D} / \mathrm{T}$ $=1, \mathrm{~h} / \mathrm{D}=1$, four baffles $\mathrm{b} / \mathrm{T}=0.1$ )

2. Smaller unit: $T_{2}=200 \mathrm{~mm}, H_{2}=200 \mathrm{~mm}, D_{2}=66.7 \mathrm{~mm}$.

Water (density $\rho_{l}=1000 \mathrm{~kg} / \mathrm{m}^{3}$, dynamic viscosity $\mu=1 \mathrm{mPa} \cdot \mathrm{s}$ ) was used as the working liquid and silicious sand (volumetric concentration $C_{V}=5 \%$, mean diameter of particles (median) $d=0.325 \mathrm{~mm}$, density $\rho_{s}=2600 \mathrm{~kg} / \mathrm{m}^{3}$, degree of hardness " 7.5 ") was used as solid particles. Pitched blade impellers with four adjustable inclined plane blades (see Fig. 2) made of rolled brass were used for the erosion tests. As independent variables we took the size of the mixing 


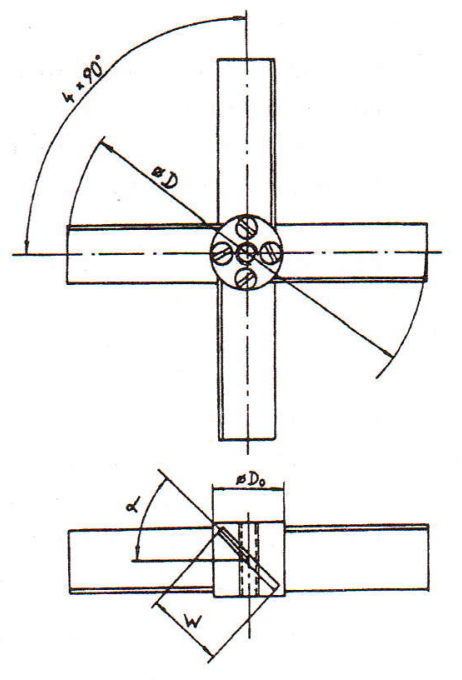

Fig. 2: Design of a pitched blade impeller with four inclined plane adjustable blades

$\left(\mathrm{D}_{1}=100 \mathrm{~mm}, \mathrm{D}_{01}=25 \mathrm{~mm}, \mathrm{~W}_{1}=20 \mathrm{~mm}\right.$,

$\mathrm{s}_{1}=1.2 \pm 0.04 \mathrm{~mm} ; \mathrm{D}_{2}=66.7 \mathrm{~mm}, \mathrm{D}_{02}=20 \mathrm{~mm}$,

$\mathrm{W}_{2}=13.3 \mathrm{~mm}, \mathrm{~s}_{2}=0.8 \pm 0.04 \mathrm{~mm} ; \alpha=30^{\circ}, 45^{\circ}$ )

equipment (see above) and the frequency of the impeller revolution $n$, at two levels of pitch angle $\alpha$. In all cases the frequency of the impeller revolution was kept under conditions of complete homogeneity of suspension when a turbulent regime of flow of the agitated batch took place. For the experiments we used cylindrical metal baffled vessels made of stainless steel (see Fig. 1). We used directly controlled alternating current electric drives of impellers with simultaneous measurement and control of the impeller frequency of revolutions within an accuracy $\pm 1 \%$ from the set up value. For the larger pilot plant unit, three levels of frequency were chosen $n_{1}=500,700,900$ RPM and for smaller one two frequencies $n_{2}=700,900$ RPM.

During the experiments the shape of the blade profile was determined from magnified copies of the worn impeller blades copied via a scanner to the PC (magnification ratio $2: 1$ ). The average course of the blade profile for the given length of the erosion process was determined as an average curve from four individual worn impeller blades.

The investigation of the shape of the worn blade was completed by determining its weight. All four blades were weighed on a scale with an accuracy $\pm 5 \mathrm{mg}$ and an average decrease of the blade $\Delta m$ from the weight of the unworn blade $m_{0}$ was calculated at the given time period of the erosion process. In this way, the dependence of the quantity $\Delta w / w_{0}$ on time was obtained.

\section{Results and discussion}

Four series of experiments were evaluated: an investigation of pitched blade impellers with pitch angle $\alpha=30^{\circ}$ for both the larger and the smaller pilot plant systems and also pitched blade impellers with pitch angle $\alpha=45^{\circ}$, again, for the larger and smaller pilot plant systems.

During the erosion process of the pitched blade impeller caused by solid particles of silicious sand, its metal plane blades change shape mainly around the leading edge $[3,4]$.

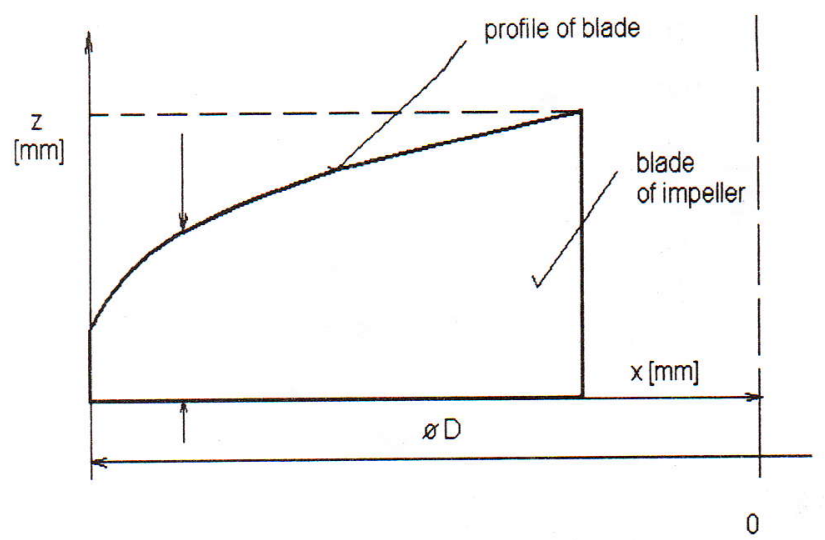

Fig. 3: Radial profile of the leading edge of the worn blade of a pitched blade impeller

The radial profile of the worn blade can be considered in dimensionless exponential form (see Fig. 3)

$$
H(X)=1-C \exp [k(1-X)] \text {, }
$$

where the dimensionless axial (vertical) coordinate along the width of the blade is

$$
H=z(x) / w
$$

and the dimensionless longitudinal (radial) coordinate along the radius of the blade is

$$
X=2 x / D \mathrm{X}=2 \mathrm{x} / \mathrm{D} \text {. }
$$

The value of the parameters of Eq. (1) - the wear rate constant $k$ and the geometric parameter of the worn blade $C$ were calculated by the least squares method from the experimentally found profile of the worn blade; each curve was calculated from $14-16$ points $(X, H)$ with a regression coefficient better than $R=0.970$.

Figs. $4-7$ illustrate examples of the dependence of the wear rate constant $k$ on the duration of the erosion process $t$ for the given size of impeller (pilot plant equipment) $D_{1}$ or $D_{2}$ and impeller pitch angle $\alpha$. The figures show that after an initial period, when parameter $k$ depends on time, the main part of this dependence exhibits a constant value of the parameter independent of time. Such independence corresponds to the model idea [3] that the wear rate constant cannot be a function of time. Nevertheless, the blade erosion mechanism at the beginning of the process cannot be described by means of the constant rate of erosion, although the calculated value $k$ fits the experimental data in this part of the erosion process very well. As was found recently [3, 4], parameter $k$ depends

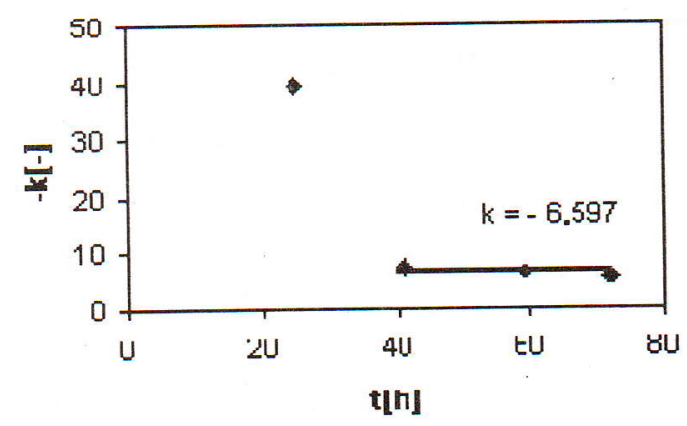

Fig. 4: Dependence of the wear rate constant on the duration of the erosion process $\left(T_{1}=300 \mathrm{~mm}, \alpha=30^{\circ}, n=900 \mathrm{RPM}\right)$ 


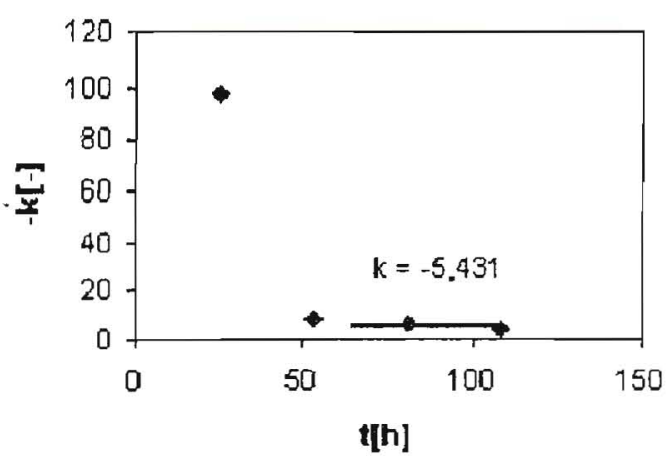

Fig. 5: Dependence of the wear rate constant on the duration of the erosion process $\left(T_{1}=300 \mathrm{~mm}, \alpha=45^{\circ}, n=700 \mathrm{RPM}\right)$

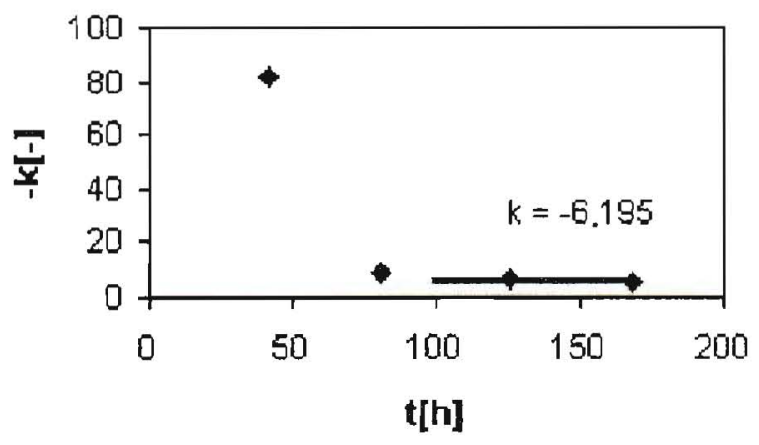

Fig. 6: Dependence of the wear rate constant on the duration of the erosion process $\left(T_{1}=300 \mathrm{~mm}, \alpha=30^{\circ}, n=500 \mathrm{RPM}\right)$

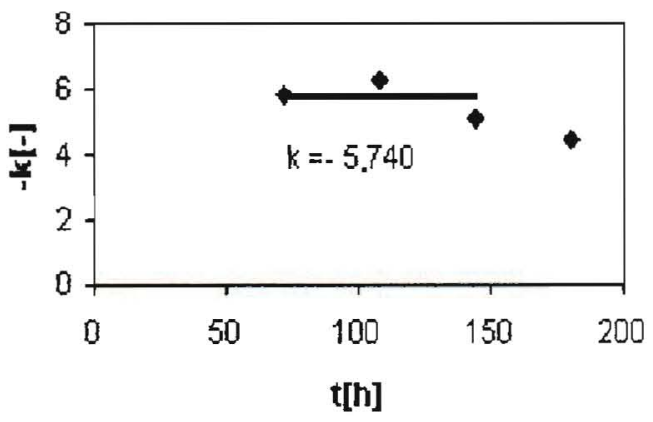

Fig. 7: Dependence of the wear rate constant on the duration of the erosion process $\left(T_{2}=200 \mathrm{~mm}, \alpha=45^{\circ}, n=700 \mathrm{RPM}\right)$

Table 1: Dependence of parameter $k$ on the process parameters of agitated systems

\begin{tabular}{|c|c|c|c|}
\hline$T[\mathrm{~m}]$ & $\alpha\left[^{\circ}\right]$ & $n\left[\mathrm{~s}^{-1}\right]$ & $-k[-]$ \\
\hline 0.300 & \multirow{3}{*}{30} & 8.3 & 6.20 \\
\cline { 3 - 4 } & & 11.7 & 6.29 \\
\cline { 2 - 4 } & \multirow{3}{*}{45} & 15.0 & 6.60 \\
\cline { 3 - 4 } & & 8.3 & 5.70 \\
\hline & & 11.7 & 5.43 \\
\hline \multirow{2}{*}{0.200} & \multirow{2}{*}{30} & 15.0 & 5.88 \\
\hline & & 11.7 & 6.58 \\
\hline \multirow{2}{*}{45} & 15.0 & 6.25 \\
\hline & & 11.7 & 5.74 \\
\hline & & 15.0 & 5.43 \\
\hline
\end{tabular}

significantly on the pitch angle: the lower the pitch angle, the higher the rate of the erosion process for all investigated conditions in the pilot plant equipment. Table 1 summarizes the value of parameter $k$. It follows from the Table that for the given blade pitch angle the wear rate constant is independent of both the impeller revolution frequency and the size of the mixing equipment. Thus it seems to be a universal parameter dependent only on impeller design.

Fig. 8 - 11 illustrate examples of the dependence of the geometric parameter of the worn blade on quantity $t$. Parameter $C$ is linearly dependent on the duration of the process in a period when no reduction of the impeller diameter takes place. When this phenomenon occurs the shape of the worn blade does not change and, then, the value of parameter $C$

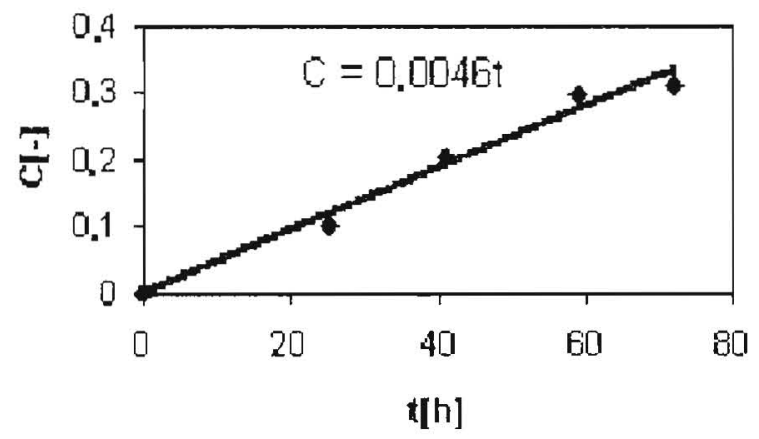

Fig. 8: Dependence of the worn blade geometric parameter on the duration of the erosion process $\left(T_{1}=300 \mathrm{~mm}, \alpha=30^{\circ}\right.$, $n=900$ RPM)

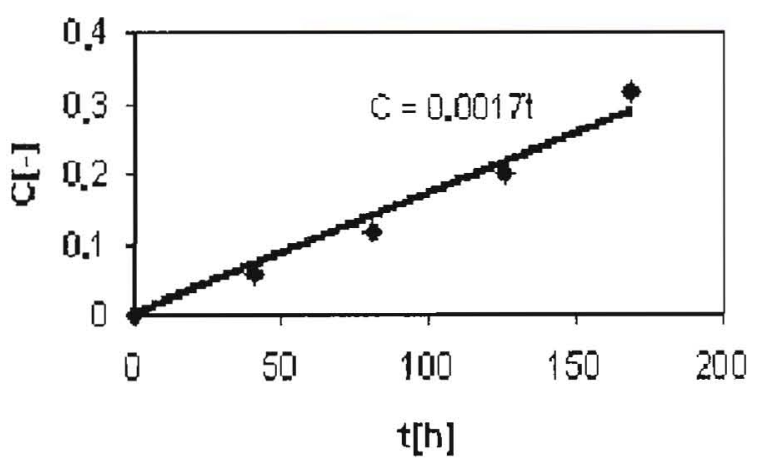

Fig. 9: Dependence of the worn blade geometric parameter on the duration of the erosion process $\left(T_{1}=300 \mathrm{~mm}, \alpha=30^{\circ}\right.$, $n=500 \mathrm{RPM}$ )

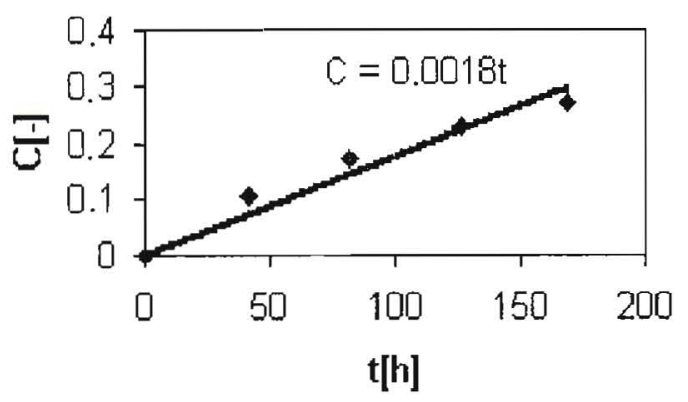

Fig. 10: Dependence of the worn blade geometric parameter on the duration of the erosion process $\left(T_{1}=300 \mathrm{~mm}\right.$, $\alpha=30^{\circ}, n=500$ RPM) 


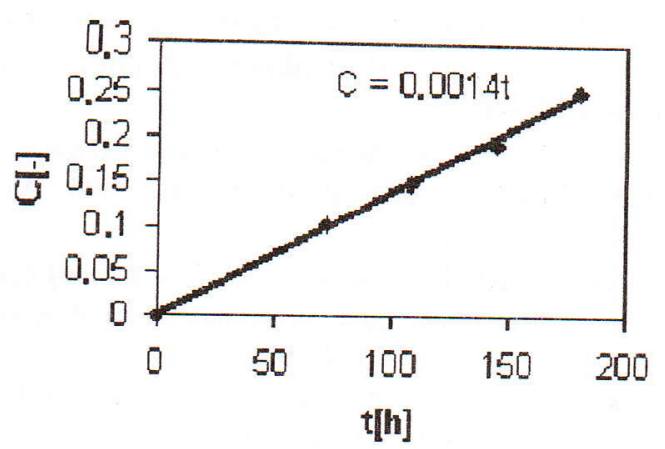

Fig. 11: Dependence of the worn blade geometric parameter on the duration of the erosion process $\left(T_{1}=200 \mathrm{~mm}\right.$, $\alpha=45^{\circ}, n=500 \mathrm{RPM}$ )

remains constant, i.e. the presented model is valid until the erosion process causes a reduction of the impeller diameter. The values of parameter $C$ depend on the pitch angle of the blades: the lower the pitch angle, the higher the slope $c$ of the linear dependence

$$
C=c \cdot t \text {. }
$$

Table 2 summarizes all values of parameter $c$ in Eq. (4) at various investigated conditions for both sizes of the pilot plant mixing equipment as well as at various impeller frequencies of revolution $n$. Finally we calculated the ratio of parameter $c$ and the impeller tip speed $\pi D n$. The values of this ratio are also written in Table 2 . The Table shows that the value of the geometric parameter of the erosion process of the worn blade depends at the given impeller pitch angle on the impeller tip speed. The results of our experiments show a linear dependence between these two quantities.

Table 2: Dependence of parameter $c$ on the process parameters of agitated systems

\begin{tabular}{|c|c|c|c|c|}
\hline$T[\mathrm{~m}]$ & $\alpha\left[^{\mathrm{O}}\right]$ & $n\left[\mathrm{~s}^{-1}\right]$ & $c \cdot 10^{7}\left[\mathrm{~s}^{-1}\right]$ & $(c / \pi D n) \cdot 10^{7}\left[\mathrm{~m}^{-1}\right]$ \\
\hline \multirow{3}{*}{0.300} & \multirow{3}{*}{30} & 8.3 & 6.67 & 2.56 \\
\cline { 3 - 5 } & & 11.7 & 9.44 & 2.57 \\
\cline { 3 - 5 } & \multirow{3}{*}{45} & 15.0 & 12.78 & 2.71 \\
\cline { 3 - 5 } & & 8.3 & 5.00 & 1.92 \\
\cline { 3 - 5 } & & 11.7 & 5.95 & 1.65 \\
\cline { 3 - 5 } & \multirow{3}{*}{30} & 15.0 & 8.61 & 1.83 \\
\cline { 3 - 5 } & & 11.7 & 6.30 & 2.56 \\
\cline { 3 - 5 } & \multirow{3}{*}{45} & 15.0 & 8.78 & 2.76 \\
\cline { 3 - 5 } & & 11.7 & 3.88 & 1.59 \\
\cline { 3 - 5 } & & 15.0 & 5.73 & 1.80 \\
\hline
\end{tabular}

Figs. 12 and 13 illustrate the time dependence of the relative decrease of the average weight of the worn blade $\Delta m / m_{0}$ at different pitch angles and frequencies of impeller revolution for both sizes of the agitated system. Here quantity $m_{0}$ characterizes the weight of the unworn blade at the very beginning of the erosion process. It is clear from all the figures that the quantity $\Delta m / m_{0}$ increases almost linearly with time. It seems that with running time after some interval the rate of blade weight reduction decreases, especially at the lowest level of

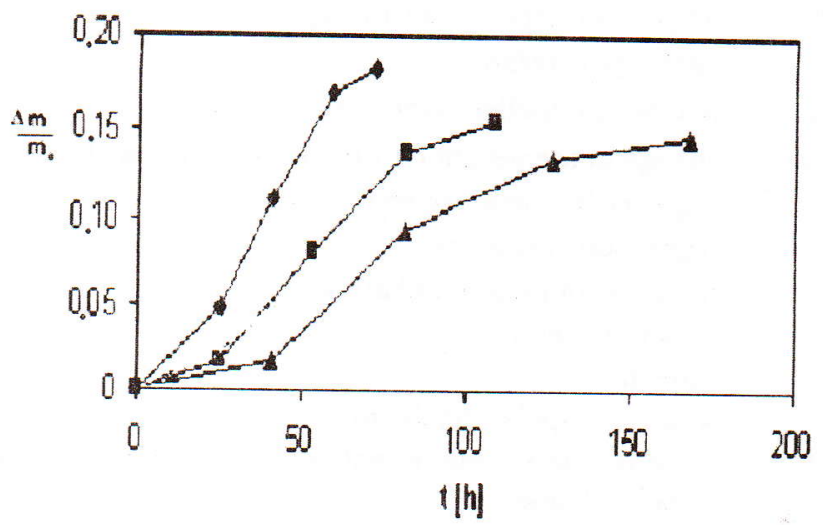

Fig. 12: Dependence of the average relative decrease of the weight of the worn blade on time $\left(T_{1}=300 \mathrm{~mm}, \alpha=30^{\circ}\right.$, $-n=500 \mathrm{RPM},-n=700 \mathrm{RPM},-n=900 \mathrm{RPM})$

impeller speed. Generally, the lower the blade pitch angle and the higher the frequency of revolution of the impeller, the higher the dependence of quantity $\Delta m / m_{0}$ on time.

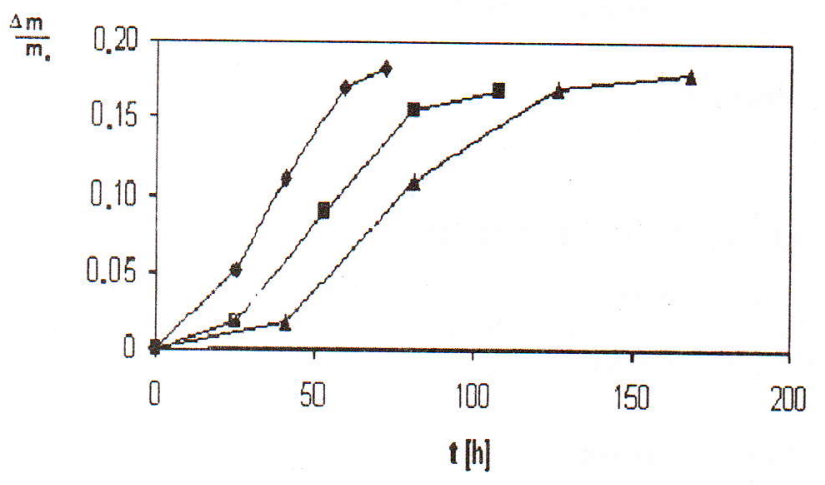

Fig. 13: Dependence of the average relative decrease of the weight of the worn blade on time $\left(T_{1}=300 \mathrm{~mm}, \alpha=45^{\circ}\right.$, $-n=500 \mathrm{RPM},-n=700 \mathrm{RPM},-n=900 \mathrm{RPM})$

\section{Conclusions}

The rate of the erosion process of the pitched blade impeller in a solid-liquid suspension of a high degree of hardness of its solid particles can be described by a universal kinetic equation with two parameters. The erosion rate constant is independent both of the size and of the frequency of revolution of the pitched blade impeller, and the second parameter (the geometric parameter of the profile of the worn blade) depends on the impeller tip speed.

\section{List of Symbols}

\section{b}

\section{C}

$C_{1}$

$c$

D

$D_{0}$ $d$

average diameter of solid particles, $m$

$H$ dimensionless axial coordinate of the profile of the worn blade

$H$ height of liquid from bottom of the vessel, $\mathrm{m}$ 
$h$ off-bottom impeller clearance, $\mathrm{m}$

$k$ wear rate constant

$m \quad$ weight of impeller blade, $\mathrm{kg}$

$\Delta m \quad$ change in the weight of impeller worn blade, $\mathrm{kg}$

$n$. impeller frequency of revolution, $\mathrm{s}^{-1}$

$R \quad$ regression coefficient

$s \quad$ thickness of impeller blade, $m$

$T \quad$ vessel diameter, $m$

$t$ time, h

$W \quad$ width of impeller blade, $m$

$X$ dimensionless longitudinal coordinate the radius of impeller blade

$x \quad$ longitudinal (radial) coordinate along the radius of impeller blade, $\mathrm{m}$

$z \quad$ axial (vertical) coordinate along the width of the blade, $\mathrm{m}$

$\alpha \quad$ pitch angle of blade, ${ }^{\circ}$

$\rho \quad$ density, $\mathrm{kg} \mathrm{m}^{-3}$

$\mu \quad$ dynamic viscosity, $\mathrm{Pa} \cdot \mathrm{s}$

Subscripts

$0 \quad$ initial value

\section{Acknowledgement}

This research has been supported by Research Project of the Ministry of Education of the Czech Republic J04/98:212200008.

\section{References}

[1] Míšek, L., Fořt, I., Havelka, K., Hoch, K.: Study of Wear and Tear of Impellers with Inclined Plane Blades. CHISA International Congress, 1990, Prague (Czechoslovakia).
[2] Fořt, I., Ambros, F., Medek, J.: Study of Wear and Tear of Axial Flow Impellers. Proceedings of the Fluid Mixing VI Conference (Editor: H. Benkreira), Bradford (England) 1999, p. 59-68.

[3] Fořt, I., Ambros, F., Medek, J.: Study of Wear of Pitched Blade Impellers. Acta Polytechnica, 2000, Vol. 40, No. 5-6, p. 5-10.

[4] For̆t, I., Medek, J., Ambros, F.: Erosion Wear of Axial Flow Impellers in a Solid-liquid Suspension. Acta Polytechnica, 2001, Vol. 41, No. 1, p. 23-28.

[5] Kipke, K.: Erosiver Verschleiss von Rührorganen. Chem. Ing. - Tech., 1980, Vol. 52, p. 658-659.

[6] Hutchings, I. M.: Wear by Particulates. Chem. Eng. Sci. 1987, Vol. 42, No. 4, p. 869-878.

[7] Strek, F.: Mixing and Mixing Equipment (in Czech): SNTL, Praha, 1978

Doc. Ing. Ivan Fořt, DrSc.

phone: +420224353633

e-mail: fort@fsid.cvut.cz

Department of Process Engineering

Ing. Viktor Kreibich, CSc.

phone: +420224352626

e-mail: viktor.kreibich@fs.cvut.cz

Department of Manufacturing Technology

Ing. Jiři Marek

jiri.marek@fsv.cvut.cz

Czech Technical University in Prague

Faculty of Mechanical Engineering

Technická 4

16607 Prague 6, Czech Republic 